\title{
Clinical Reasoning: A patient with a history of weight loss presenting with seizures
}

Garland Tang, MD, and David R. Benavides, MD, PhD

Neurology ${ }^{\circledR}$ 2020;95:e2038-e2042. doi:10.1212/WNL.0000000000010344

Correspondence

Dr. Benavides

dbenavides@

som.umaryland.edu

\section{Section 1}

A 55-year-old right-handed man presented to the hospital following an episode at home described as unresponsiveness and generalized convulsions. Upon arrival to the emergency department, the patient had 4 clinically similar events noted as unresponsive with generalized convulsions without return to baseline between events. The patient did not have a history of seizures, CNS infection, head trauma, or febrile seizures as a child, or family history of seizures. The patient had an unremarkable state of health until approximately 1 year prior to current presentation. At that time, he reported abdominal pain, diarrhea, and weight loss of 50 pounds over 1 year. Following work-up, he was diagnosed with Crohn disease and treated with infliximab. He also reported progressive hearing loss in the left ear 8 months prior to the current presentation. The patient was transferred 7 days after reported seizure at home. His examination upon transfer was notable for temperature of $37.8^{\circ} \mathrm{C}$, blood pressure of $138 / 80 \mathrm{~mm} \mathrm{Hg}$, pulse of 146 , respiratory rate of 29 , and oxygen saturation of $100 \%$ on room air. He was $55^{\prime} 8^{\prime \prime}$ and weight was 96 pounds 3.2 ounces.

On neurologic examination, the patient was inattentive and provided delayed but appropriate responses to orientation, naming, repetition, and comprehension. He had unremarkable funduscopic examination, pupillary reflexes, extraocular movements, and smile, sensorineural hearing loss in his left ear, and normal tongue protrusion. He had diffuse muscle wasting with decreased strength symmetrically $4 / 5$ and $3+$ reflexes in upper and lower extremities with flexor plantar responses. Otherwise, his neurologic examination was unremarkable. An MRI brain with and without gadolinium demonstrated $\mathrm{T} 2$ hyperintense lesions in right temporal lobe, right thalamus, bilateral mesial temporal lobes, bilateral middle cerebellar peduncles, and left dorsal pons (figure) with no evidence of contrast enhancement. Continuous EEG demonstrated lateralized periodic discharges primarily in the right temporo-parietal region with fast activity and rhythmic activity. CSF analysis yielded total nucleated cell count of 101 cells $/ \mathrm{mm}^{3}$ with $87 \%$ lymphocytes, red cell count of 74 cells $/ \mathrm{mm}^{3}$, glucose $40 \mathrm{mg} / \mathrm{dL}$, and protein $177 \mathrm{mg} / \mathrm{dL}$.

\section{Questions for consideration:}

1. What are the differential diagnoses at this point?

2. What additional testing would you perform? 
Figure Fluid-attenuated inversion recovery MRI on day 7 after symptom onset

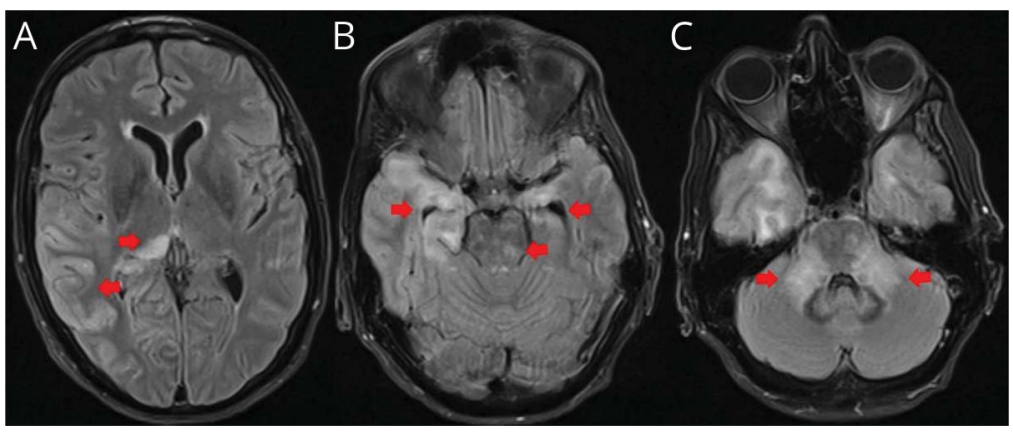

Representative sequences demonstrating T2 hyperintensities in the (A) right pulvinar, right parieto-occipital cortex, (B) bilateral mesial temporal lobes, left dorsal pons, and (C) bilateral middle cerebellar peduncles. Red arrows denote abnormalities.

\section{GO TO SECTION 2}




\section{Section 2}

The patient is a 55-year-old man, immunosuppressed for Crohn disease, presenting with status epilepticus, encephalopathy, chronic hearing loss, and chronic weight loss. The constellation of his clinical presentation, systemic symptoms, abnormal imaging results, and CSF analysis suggested an underlying systemic disorder that included infectious, neuroinflammatory, vascular, neoplastic, and paraneoplastic etiologies.

Multiple infectious etiologies were considered in this immunosuppressed patient. Common bacterial, viral, fungal, and parasitic causes of meningoencephalitis were investigated using CSF testing. Tropheryma whipplei was of particularly high concern due to concurrent neurologic and gastrointestinal symptoms commonly seen in CNS Whipple disease. Autoimmune and neuroinflammatory disorders including neurosarcoidosis, Sjögren disease, systemic lupus erythematous (SLE), and rheumatoid arthritis (RA) can cause a myriad of neurologic symptoms including encephalopathy and seizures. Sarcoidosis can cause gastrointestinal symptoms. Immunoglobulin G4 (IgG4)-related disease can present with weight loss and systemic and CNS involvement. The patient did not have rashes, xerostomia, keratoconjunctivitis sicca, or joint pain to suggest Sjögren disease, SLE, or RA. Tumefactive demyelinating process, myelin oligodendrocyte glycoprotein antibody-associated disease, and infliximab-associated CNS demyelination can cause MRI lesions as described. Regarding vascular etiologies, Susac syndrome and primary CNS vasculitis were also considered. Susac syndrome is an autoimmune vascular disease that causes a triad of hearing loss, visual impairment, and encephalopathy. The patient presented with chronic hearing loss and acute encephalopathy; notably, the triad of symptoms do not all have to present concurrently. Vasculitis can present with encephalopathy, seizures, and focal neurologic deficits depending on the location of vessel involvement. A CNS neoplasm, paraneoplastic limbic encephalitis, carcinomatous meningitis, or lymphoma can present with this clinical picture if localized to the temporal lobe, the cerebellopontine angle, or the surrounding meninges.
Additional CSF, serologic, imaging, and biopsy tests were performed. CSF immunoglobulin $\mathrm{G}$ ( $\mathrm{IgG}$ ) index was elevated at 1.34, and oligoclonal bands were present. CSF angiotensin-converting enzyme (ACE) level was elevated at $4.8 \mu \mathrm{mol} / \mathrm{L} / \mathrm{min}$. CSF T whipplei PCR was negative. PCR tests on CSF were negative for the following: herpes simplex virus $1 / 2$, varicella-zoster virus, Epstein-Barr virus, cytomegalovirus, human parechovirus, Listeria monocytogenes, Escherichia coli K1, Haemophilus influenzae, Neisseria meningitidis, Streptococcus agalactiae, Streptococcus pneumoniae, Lyme disease, West Nile virus, and Mycobacterium tuberculosis. CSF bacterial culture, fungal culture, cryptococcal antigen, and acid-fast bacilli culture were negative. CSF flow cytometry, CSF cytology, and Mayo autoimmune encephalopathy CSF panel tests were negative. Serum electrophoresis showed normal IgG subclasses, including IgG4 levels. Serum testing for Mayo serum paraneoplastic autoantibody evaluation, antinuclear antibodies, ribonucleoprotein, anti-Smith, rheumatoid factor, and anti-Ro/La were negative. CT angiography showed no evidence of vasculitis. CT chest did not demonstrate hilar/mediastinal lymphadenopathy. A whole body PET/CT did not demonstrate hyperactive metabolic activity to suggest a primary neoplasm or lymphoma.

Gastrointestinal biopsies were obtained from the stomach, small intestine, and large intestine. Histopathologic analyses demonstrated chronic and active enteritis with cryptitis, extensive granuloma formation in the stomach, and poorly formed granulomas in the terminal ileum. There was no evidence of periodic-acid Schiff-positive macrophages, which are commonly seen with Whipple disease. ${ }^{1}$ Biopsies from superficial temporal lobe, deep temporal lobe, and dura revealed perivascular non-necrotizing granulomas with chronic mixed T-lymphocytic inflammation.

\section{Questions for consideration:}

1. What is the diagnosis?

2. What treatment should the patient receive for acute therapy and maintenance therapy?

GO TO SECTION 3 


\section{Section 3}

The clinical presentation and diagnostic testing allowed for the definitive diagnosis of neurosarcoidosis with digestive tract sarcoidosis. Neurosarcoidosis is a granulomatous inflammatory disease of unknown etiology characterized by a multitude of symptoms affecting the CNS or peripheral nervous system (PNS). The differential of other disorders that cause noncaseating granulomas is extensive, ${ }^{2}$ but alternatives, including primary immunodeficiency, lymphoma, Crohn disease, and common variable immunodeficiency were not supported by the extensive workup performed in this patient.

The first-line therapy for neurosarcoidosis is $1 \mathrm{~g}$ IV methylprednisolone for 2-5 days followed by oral prednisone $0.5-1.0 \mathrm{mg} / \mathrm{kg} / \mathrm{d}$ to a maximum dose of $90 \mathrm{mg} / \mathrm{d}$ for $2-4$ weeks. ${ }^{3,4}$ Typically, prednisone is weaned to $0.25-0.5 \mathrm{mg} / \mathrm{kg} /$ $\mathrm{d}$ by 4 months and then weaned off by $2-3$ years if there are no relapses. Maintenance immunotherapy is often required to control disease. Long-term immunosuppression exposes patients to increased infection risk. Second-line therapy for neurosarcoidosis typically involves a steroid-sparing immunosuppressive therapy such as methotrexate, azathioprine, and mycophenolate mofetil along with oral prednisone. ${ }^{3,5}$ Third-line therapy is a tumor necrosis factor- $\alpha$ inhibitor, particularly infliximab, which demonstrated favorable radiographic and clinical improvement in previously refractory cases of neurosarcoidosis. ${ }^{5,6}$

\section{Discussion}

Recent diagnostic criteria for neurosarcoidosis from the Neurosarcoidosis Consortium Consensus Group stated that a definitive diagnosis of neurosarcoidosis required typical clinical manifestations, MRI findings, CSF results, and nervous system pathology of granulomatous inflammation after rigorous exclusion of other causes. ${ }^{4}$ EMG/NCS may be used to demonstrate evidence of PNS involvement in neurosarcoidosis.

The most commonly reported neurologic symptoms in neurosarcoidosis are headache, fatigue, sensory abnormalities, gait abnormalities, visual impairment, hearing impairment, seizures, ataxia, and vertigo. ${ }^{4}$ The most common clinical manifestations are cranial neuropathy, meningitis, hydrocephalus, endocrinopathy, seizures, myelopathy, and peripheral neuropathy. ${ }^{4}$ The most common CSF findings associated with neurosarcoidosis are elevated CSF protein, lymphocytic pleocytosis, elevated CSF ACE, elevated IgG index, and oligoclonal bands. ${ }^{7}$ The pathologic hallmark of CNS neurosarcoidosis is noncaseating granulomas typically containing epithelioid cells, giant cells, and lymphocytes surrounded by lymphocytes and plasma cells in a perivascular distribution of the parenchyma. ${ }^{4}$
This patient met the definitive criteria for CNS neurosarcoidosis, type A, with evidence of extraneural sarcoidosis. He exhibited sensorineural hearing loss consistent with a cochlear neuropathy, seizures, and fatigue. He had common CSF findings including elevated CSF protein, lymphocytic pleocytosis, elevated CSF ACE, elevated IgG index, and oligoclonal bands. He had an extensive workup that did not identify an alternative diagnosis. The severity of his clinical syndrome and lack of definitive diagnosis warranted pursuit of biopsy of brain and gastrointestinal tissue. These biopsies were critical to securing the diagnosis of neurosarcoidosis. The parenchymal and dural brain biopsy demonstrated the typical noncaseating granulomas with surrounding lymphocytes and plasma cells. The gastrointestinal biopsy demonstrated extensive granuloma formation seen in the stomach typical of digestive tract sarcoidosis. Digestive tract sarcoidosis is particularly rare, with a prevalence rate of $0.6 \%-1.6 \%{ }^{8} \mathrm{~A}$ concurrent presentation of CNS neurosarcoidosis and digestive tract sarcoidosis is exceedingly rare based on literature review.

During his hospitalization, the patient received IV methylprednisolone followed by oral prednisone with a slow taper, IV immunoglobulins, and plasma exchange. His seizures were well controlled on levetiracetam, valproic acid, and phenytoin. He had symptomatic improvement of his hearing loss and encephalopathy and gained 50 pounds within 3 months of hospitalization for seizures. Valproic acid may have contributed to his weight gain. Repeat MRI during the hospitalization demonstrated decreased T2-hyperintense lesions. He is maintained on mycophenolic acid and infliximab as maintenance immunotherapy and has been weaned off oral prednisone. At 12 months postdischarge, he shows evidence of continued recovery with no further seizures. He has returned to work with residual moderate left ear hearing impairment.

\section{Study funding}

No targeted funding reported.

\section{Disclosure}

D.R. Benavides is supported by research grants from NIH/ NINDS (1K08NS114039) and University of Maryland School of Medicine (seed grant). G. Tang reports no disclosures relevant to the manuscript. Go to Neurology.org/ $\mathrm{N}$ for full disclosures.

\section{Appendix Authors}

\begin{tabular}{lll}
\hline Name & Location & Contribution \\
\hline $\begin{array}{l}\text { Garland Tang, } \\
\text { MD }\end{array}$ & $\begin{array}{l}\text { University of Maryland } \\
\text { School of Medicine, } \\
\text { Baltimore }\end{array}$ & Drafted the manuscript \\
\hline $\begin{array}{l}\text { David R. } \\
\text { Benavides, } \\
\text { MD, PhD }\end{array}$ & $\begin{array}{l}\text { University of Maryland } \\
\text { School of Medicine, }\end{array}$ & $\begin{array}{l}\text { Revised the manuscript } \\
\text { for intellectual content }\end{array}$ \\
\hline
\end{tabular}




\section{References}

1. Fenollar F, Raoult D. Whipple's disease. Clin Diagn Lab Immunol 2001;8:1-8.

2. Timmermans WM, van Laar JA, van Hagen PM, van Zelm MC. Immunopathogenesis of granulomas in chronic autoinflammatory diseases. Clin Transl Immunol 2016;5:e118.

3. Tavee JO, Stern BJ. Neurosarcoidosis. Continuum 2014;20:545-559.

4. Stern BJ, Royal W, Gelfand JM, et al. Definition and consensus diagnostic criteria for neurosarcoidosis: from the Neurosarcoidosis Consortium Consensus Group. JAMA Neurol 2018;75:1546-1553.
5. Voortman M, Drent M, Baughman RP. Management of neurosarcoidosis: a clinical challenge. Curr Opin Neurol 2019;32:475-483.

6. Gelfand JM, Bradshaw MJ, Stern BJ, et al. Infliximab for the treatment of CNS sarcoidosis: a multi-institutional series. Neurology 2017;89:2092-2100.

7. Bridel C, Courvoisier DS, Vuilleumier N, Lalive PH. Cerebrospinal fluid angiotensin converting enzyme for diagnosis of neurosarcoidosis. J Neuroimmunol 2015;285:1-3. 8. Ghrenassia E, Mekinian A, Chapelon-Albric C, et al. Digestive-tract sarcoidosis: French nationwide case-control study of 25 cases. Medicine 2016;95:e4279. 


\section{Neurology}

Clinical Reasoning: A patient with a history of weight loss presenting with seizures Garland Tang and David R. Benavides

Neurology 2020;95;e2038-e2042 Published Online before print July 10, 2020

DOI 10.1212/WNL.0000000000010344

This information is current as of July 10, 2020

\section{Updated Information \&} Services

\section{References}

Subspecialty Collections

\section{Permissions \& Licensing}

\section{Reprints}

including high resolution figures, can be found at: http://n.neurology.org/content/95/14/e2038.full

This article cites 8 articles, 1 of which you can access for free at: http://n.neurology.org/content/95/14/e2038.full\#ref-list-1

This article, along with others on similar topics, appears in the following collection(s):

All Epilepsy/Seizures

http://n.neurology.org/cgi/collection/all_epilepsy_seizures Autoimmune diseases

http://n.neurology.org/cgi/collection/autoimmune_diseases

Encephalitis

http://n.neurology.org/cgi/collection/encephalitis

Gastrointestinal

http://n.neurology.org/cgi/collection/gastrointestinal

Status epilepticus

http://n.neurology.org/cgi/collection/status_epilepticus

Information about reproducing this article in parts (figures,tables) or in its entirety can be found online at:

http://www.neurology.org/about/about_the_journal\#permissions

Information about ordering reprints can be found online:

http://n.neurology.org/subscribers/advertise

Neurology ${ }^{\circledR}$ is the official journal of the American Academy of Neurology. Published continuously since 1951, it is now a weekly with 48 issues per year. Copyright () 2020 American Academy of Neurology. All rights reserved. Print ISSN: 0028-3878. Online ISSN: 1526-632X.

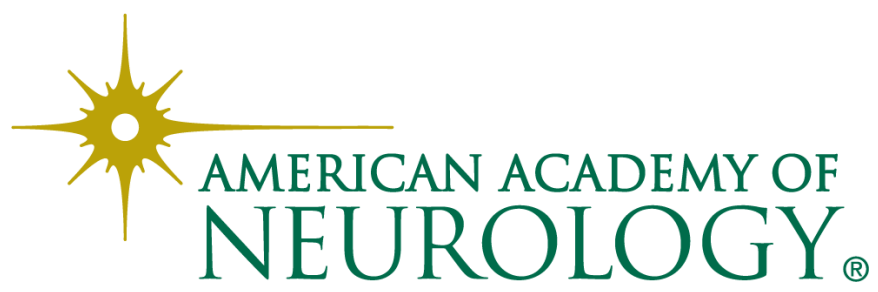

